\title{
Urban Sprawl in sub-Saharan Africa: A review of the literature
}

\section{in selected countries}

\author{
Gerald Albert Baeribameng Yiran ${ }^{1 *}$ \\ Austin Dziwornu Ablo ${ }^{1}$ \\ Freda Elikplim Asem² \\ George Owusu ${ }^{1}$
}

\begin{abstract}
Urban sprawl has gained popularity in academic discourse in recent times, but the majority of the research was conducted in developed countries. There is a marginal body of works on the character and nature of urban sprawl in Sub-Saharan Africa (SSA), although the region is experiencing one of the fastest rates of sprawl. Urbanisation in SSA is very rapid, and in addition to the emerging challenges of globalisation, climate change and poverty, SSA cities have an enormous task to manage urban sprawl. This paper reviews the literature on urban sprawl in SSA to identify research gaps and propose a research agenda. Published articles from five Anglophone countries in three of the four regional blocks in SSA were selected. The literature was organised into the causes and effects of urban sprawl and showed that the previous research on the subject focused mainly on its environmental impacts. Few studies have looked at the effects of sprawl on rural livelihoods, agriculture and food security considering the challenges of global climate change and poverty. Other studies have used Remote Sensing and Geographic Information Systems, but these were conducted largely for change detection. The paper recommends the deployment of a more comprehensive methodology incorporating remote sensing/GIS with ethnographic methods to capture better the complexity and impacts of urban sprawl in SSA. Additionally, further research attention must be paid to the effects of urban sprawl on rural livelihoods and overall sprawl-induced agrarian change.
\end{abstract}

Keywords: Urban sprawl, Urbanisation, adaptation, rural-urban communities, Sub-Sahara Africa

${ }^{1}$ Department of Geography and Resource Development, University of Ghana, Legon. ${ }^{2}$ Department of Agricultural Economics and Agribusiness, University of Ghana, Legon. *Corresponding author's email address: gyiran@ug.edu.gh

Ghana Journal of Geography Vol. 12(1), 2020 pages 1-28

https://doi.org/10.4314/gig.v12i1.1 


\section{Introduction}

The urban population in developing countries will double by 2050, rising from 2.6 billion in 2010 to 5.3 billion people (Madlener \& Sunak, 2011). Between 2005 and 2010, Africa's urban population grew on average by thirteen million people per annum and is projected to reach 25 million per annum between 2045 and 2050 (UN-DESA, 2011). Sub-Saharan Africa (SSA) has the highest urban growth rate of about 3.6\% per annum (UN, 2006). It is often regarded as the world's fastest urbanising region with an urban population of about 472 million people currently, and this figure will double over the next 25 years (Saghir \& Santoro, 2018). This rapid rate of urban growth in SSA has implications for the attainment of the Sustainable Development Goals (SDGs), especially Goal 11 which concerns developing sustainable cities and communities and good and affordable public housing schemes. Rural-urban migration is the primary driver of population growth in most urban areas (Hove et al., 2013; UN-Habitat, 2009) and increases demand for built infrastructure, resulting in the infill of undeveloped spaces and expansion into the rural areas. Other factors driving urban development include increasing income, decreasing commuting cost, preference for countryside living (people still prefer to live in a rural and less busy environment than the busy hustle and bustle in cities), relatively low housing/land prices, increasing preference for the nuclear family, land development speculation and better life-transforming opportunities in cities (Pendall, 1999; Bart, 2010; Habibi \& Asadi, 2011; Osman et al., 2016).

The current growth rate of African cities outstrips the capacity of many city authorities to provide adequate, affordable housing. To bridge the housing gap, many governments have liberalised the housing sector to allow for private sector participation in housing provision, and this has contributed to the rapid expansion of most SSA cities beyond their boundaries (see Fuseini \& Kemp, 2016; Fuseini et al., 2017). The rapid development of cities often results in urban sprawl the uncontrolled and uncoordinated expansion of a city or a metropolitan area (Johnson, 2001). The rapid sprawling of cities leads to the encroachment of urban land use on rural land (Liu et al., 2011), diminishing the spatial segregation between urban and rural areas. The transformation of the rural landscape due to urban sprawl has significant implications for agriculture and food security (Bristow \& Kennedy, 2013). 
Research on the effects of urban sprawl can be grouped into impacts on the environment (e.g. Bart, 2010), transport and energy use (Ahmadi, 2014; Rodríguez-Álvarez, 2016), public health (Frumkin, 2002) and socio-cultural changes (Hove et al., 2013; Fuseini et al., 2017). Ji et al. (2006) and many other researchers have, however, argued that research on urban sprawl is limited in developing countries and is, even worse, in SSA. Meanwhile, Africa and Asia account for about $90 \%$ of global urban population growth (the primary cause of urban sprawl), with Africa's urban population tripling by 2050 (UN-DESA, 2014). According to UNECA (2017), East Africa is the least urbanised sub-region in SSA but is urbanising the fastest, while Southern Africa, the most urbanised, is urbanising at the slowest rate. This paper is a review of the literature, purposely to examine the state of knowledge, features and direction of research on urban sprawl in selected SSA countries and identify pressing gaps for further study.

\section{Methodology}

\section{Selection of Study Countries}

There is substantial disquiet about the linkage between urbanisation and development, health, environmental degradation, poverty and social welfare in SSA (White et al., 2008). It is even more worrying as various projections into 2050 and beyond show that SSA will experience higher rates of urbanisation than any other region in the world. This review, therefore, explores the level of knowledge on urbanisation in the sub-region. We divided SSA into four sub-regional blocks West, East, Central and Southern Africa. We selected Nigeria, Kenya and South Africa, since they have the largest urban populations and Ghana, which has one of the ten fastest-growing cities in SSA (UNECA, 2017). The selected countries contain over 80 per cent of the largest and fastestgrowing cities in SSA (Figure 1). The selection was limited to only the Anglophone countries since we do not understand Portuguese and French. 


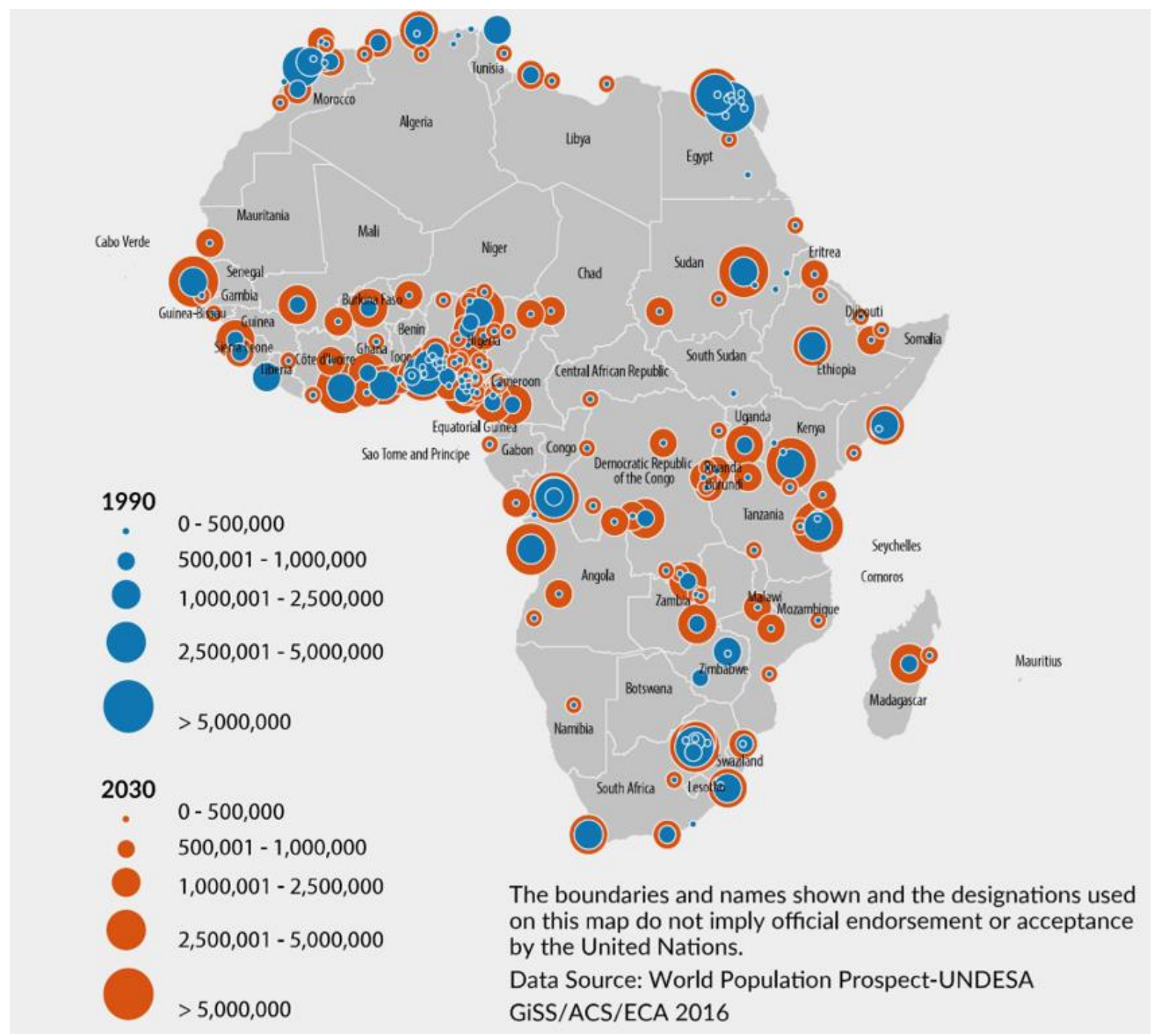

Figure 1: Map showing the largest cities by population in Africa

Source: Copied from UNECA (2017)

\section{Data Source and Content Analysis}

ScienceDirect, JSTOR, SAGE, Google and Google Scholar were the databases consulted. These databases index a wide range of journals and are outlets that the authors were able to access. Keywords used in the search were 'urbanisation', 'urban sprawl', 'urban change', 'urban expansion', 'urban land use' and 'urban growth' in combination with 'impacts', 'factors', 'drivers', 'driving forces', 'consequences', 'causes' or 'effects'. We also included country and 
sub-regional names as well as the names of the urban centres in the keywords so that we could obtain country-specific articles as well as articles that looked at the phenomenon across the subregions. The literature search was conducted in August 2017 with no time limit imposed on the literature consulted.

We excluded the articles that dealt with the physical expansion of cities and issues of urbanisation not related to urban sprawl such as those that exclusively explored land-use change. Following the selection of articles, thematic analysis using the three-step approach was done to document analysis (Huang et al., 2010; Wesley, 2010; Yiran \& Stringer, 2017). This involved:

i. A quick scan through each article to identify and highlight sections that contained the variables used to describe/explain the urban sprawl phenomenon.

ii. A thorough reading of the highlighted parts of the article to pick out keywords/variables and

iii. A grouping of variables into themes and subthemes (see results section).

A three-level categorisation was used, and it included listing the variables used to describe urban sprawl in the literature, grouping variables into subthemes and categorisation into themes. To identify the variables, we searched the literature for words or phrases such as causes, drivers, driving forces and factors responsible for urban sprawl, effects, consequences, and impacts of urban sprawl, among others. We constructed a table in Microsoft word for each theme with the articles' titles, the subthemes and variables as columns in each country. Once a variable, subtheme or theme is identified, the numeral one (1) is entered under the appropriate column in the table for that article. The citations of these articles were exported into EndNote, and the numbered reference style was used, which ensured that an article that was entered multiple times maintained the same number in the tables since some articles had more than one theme or subtheme. The tables were exported to excel and entries summed up to obtain the number of articles reporting a theme, subtheme and variable. The numbers were used to plot graphs. 


\section{Results}

The search returned over a million articles, but after a preliminary reading of their titles and abstracts, a little over 600 articles were downloaded for this review. After applying the inclusionexclusion criteria, this number reduced to 103 comprising 28 from Ghana, 27 from Nigeria, 26 from Kenya, and 22 from South Africa with two main themes on causes and effects of urban sprawl identified. The variables used to discuss the causes of urban sprawl were grouped into six subthemes (Figure 2) while those used to discuss the effects were grouped into nine subthemes (Figure 3). The variables are factors or expressions that are used directly by the authors in their discussion. The explanations of these themes/subthemes are provided in the country-level analysis.

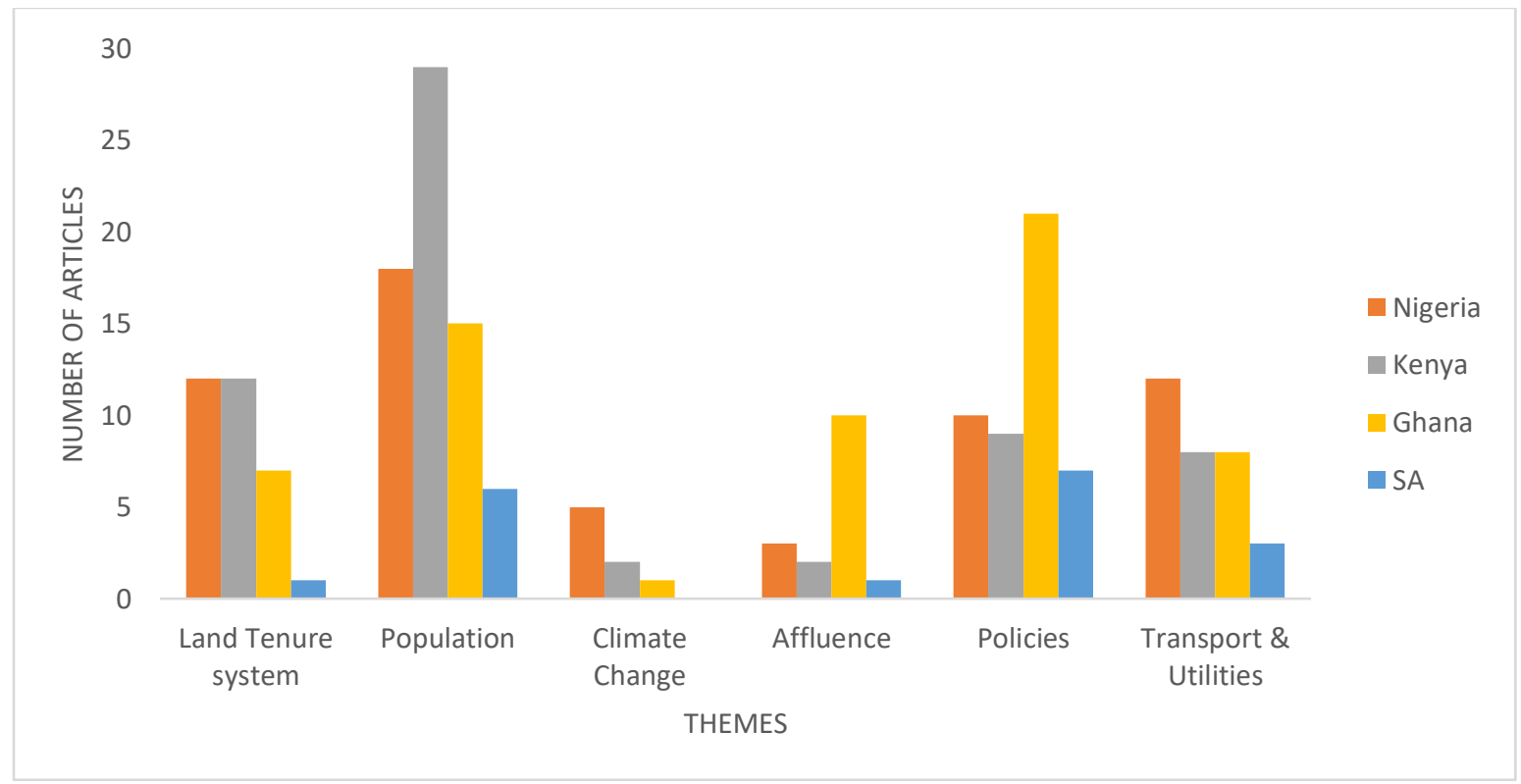

Figure 2: Causes of urban sprawl in Africa Source: Authors 


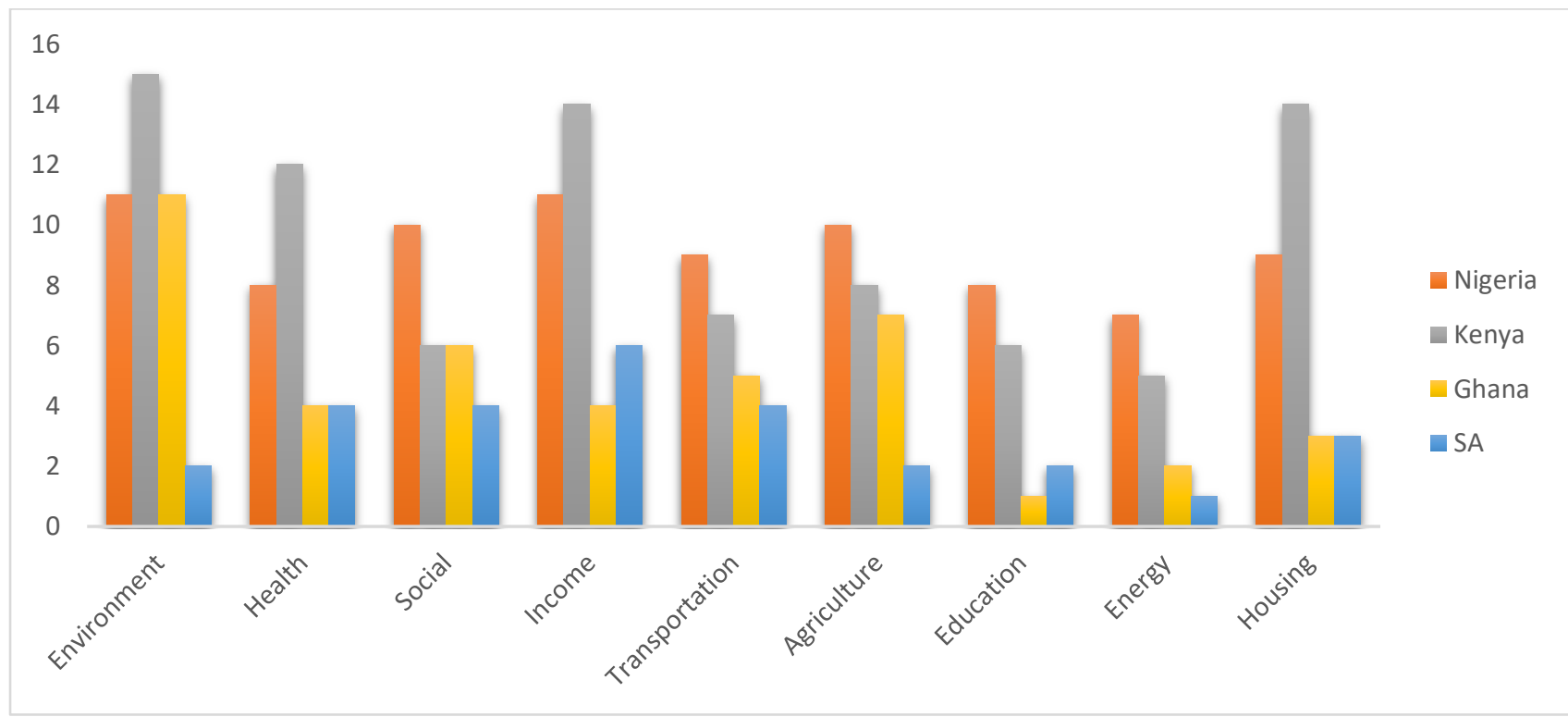

Figure 3: Effects ${ }^{1}$ of urban sprawl in sub-Saharan Africa Source: Authors' construct

In the next subsections, we present the variables used to discuss the subthemes in each of the selected countries. It is worth noting that to avoid being repetitive, factors that have been explained in one section are not repeated in subsequent sections.

\section{Urban Sprawl in Ghana}

\section{Causes of Urban Sprawl in Ghana}

The factors we grouped into the policies (Figure 2) subtheme which have been reported to cause urban sprawl include neo-liberalisation (Owusu, 2013; Fuseini et al., 2017), globalisation (Simon et al., 2004; Owusu, 2013), weak institutions (Owusu, 2013), lack of/inadequate planning schemes and non-enforcement of planning regulations (Amoateng et al., 2013; Cobbinah et al., 2017; Kleemann et al., 2017; Owusu, 2013) and of deliberate policies to make some towns economic

\footnotetext{
${ }^{1}$ The effects are both positive and negative though there was more research on the negative effects
} 
growth poles (Fuseini et al., 2017). Neo-liberalization pertained to the government, allowing private sector participation in the provision of goods and services, especially housing in the case of urban sprawl. This permitted individuals and estate agencies to acquire land from families and chiefs and develop residential facilities to bridge the growing housing gap, thus leading to development outpacing planning schemes. Also, institutions were said to be weak due to political interference, lack of logistics and above all, corruption, which makes them ineffective in enforcing building/planning regulations. In many places, the planning schemes available do not cover the areas where new residential developments are active, which allows developers to site properties without following laid down procedures and regulations. These factors have, in various ways, contributed to urban sprawl in Ghana.

The next subtheme is population growth which results in increased demand for housing. Population growth mainly resulted from natural increases including increasing nuclear/decreasing extended family systems (Simon et al., 2004; Rain et al., 2011; Owusu, 2013; Oppong \& Yeboah, 2013; Kuusaana \& Eledi, 2015; Fuseini \& Kemp, 2016; Fuseini et al., 2017, Kleemann et al., 2017, Cobbinah et al., 2017) and rural to urban migration (Simon et al., 2004; Rain et al., 2011; Cobbinah et al., 2017; Fuseini et al., 2017; Kleemann et al., 2017). Generally, population growth, mainly due to people moving to cities, as reported in the literature, results in increasing demand for infrastructure, shelter and other social activities; this, in turn, leads to conversion of more land into urban use. It was also explained that the extended family system where many people lived as one household is giving way to the nuclear family, which consists of a husband, wife and children. This has put extra pressure on the housing system because people who could have lived with their brothers and sisters, as is done in rural areas, are made to search for their accommodation.

Affluence (i.e. income levels) was related to lifestyle and included rising numbers of people in the middle-income class and their varied preferences, including the desire for neat surroundings (Amoateng et al., 2013; Oppong \& Yeboah, 2013) and the wish to avoid problems associated with renting in Ghana (Oppong \& Yeboah, 2013; Adaku, 2014). The rest of the factors in the affluence subtheme were the desire for single occupancy/low rise buildings (Oppong \& Yeboah, 2013; Owusu, 2013), family pressure on the individual to own property due to social status (Adaku, 2014; Owusu, 2013), high cost of rent resulting in the displacement of the urban poor (Cobbinah 
et al., 2017), and the general increase in demand for housing (Kleemann et al., 2017; Fuseini et al., 2017; Owusu, 2013; Simon et al., 2004). Increasing affluence or income levels come along with changing tastes and desires, and these have contributed to urban sprawl, according to the literature. These studies indicated that there was an increase in the number of people in the middle and upper economic classes. Once they could afford a home and a car, their tastes changed. The tastes or preferences varied from whether they wanted big houses, large compounds, beautiful landscaped environments or swimming pools in the house, among others, so that they bought or built their own homes at a fast rate, thus increasing the extent of the city faster than could have been imagined by city authorities. Another factor that compelled the higher economic class is the extortion by property owners who increased their rents exorbitantly on every renewal date.

Transportation and utilities were another subtheme that caused urban sprawl. The factors that made transportation a cause of urban sprawl include expansion of and good road network in the suburban areas (Amoateng et al., 2013; Owusu, 2013; Kleemann et al., 2017; Fuseini et al., 2017) and utilities including provision/extension of water and electricity (Simon et al., 2004; Fuseini \& Kemp, 2016; Kleemann et al., 2017). According to the literature, people moving to suburban areas have cars and require roads. However, because most of these areas are outside the planning zones of the cities, there are no roads. An analysis of unpublished data collected for studies on urban sprawl in Accra indicates that the initial road network is constructed by individuals or a group who pull their resources together to remove tree stumps and level the road to their properties. Once the area begins to densify, pressure is put on the government to gravel the roads and later surface them with bitumen. A similar process applies to electricity, whereby people buy poles and erect them near their properties and electricity companies only connect the premises to the power supply. For water, many use groundwater or rely on tanker services until the water supply company extends supply lines to the area. These issues are not so difficult for the affluent to resolve since their comfort is a priority, and therefore this contributes to fueling the sprawl.

Land tenure related causes include unregulated land sales (Simon et al., 2004; Amoateng et al., 2013), compulsory land acquisition and land title registration (Owusu, 2013), speculation that land prices will soon go higher or residential development will reach there sooner (Kuusaana \& Eledi, 2015), land ownership/management (Amoateng et al., 2013, Kleemann et al., 2017), low land 
values at the outskirts (Amoateng et al., 2013, Kuusaana \& Eledi, 2015) and high land prices for other uses than agriculture (Peprah, 2014; Kuusaana \& Eledi, 2015), all of which result in the easy acquisition of land for building. Land in Ghana is primarily owned by individuals, families and stools/skins who dispose of it when there is demand for it or the family/individual needs money. Our experience in Ghana (and this may apply across several SSA countries) is that the family/individual engages surveyors to demarcate the land into plots of $70 \mathrm{ft}$ by $100 \mathrm{ft}$ which are sold to prospective developers. The prices of these plots in the outskirts of cities are lower than those in the city, so people purchase either single plots or in bulk if they have the means.

One article (Rain et al., 2011) reported climate change and related climatic events, especially flooding and subsequent pollution of water, as a cause of sprawl. In this case, flooding of certain parts of cities makes people move out of those places to areas without flooding, mostly to the outskirts, where rent or land prices are relatively lower. The reason climate change did not feature prominently as a cause, as is the case in other countries, is that climate change is largely seen as a driver of migration from rural to urban areas. Thus, the literature indicates immediate causes rather than remote ones.

\section{Effects of Urban Sprawl in Ghana}

Not surprisingly, the effects (Figure 3) received more attention than the causes (Figure 2). Environmental impacts were most popular, and these are shown in Table 1. 
Table 1: Variables describing the environmental effects of urban sprawl

\begin{tabular}{ll}
\hline Factors & References \\
\hline Unsustainable residential development & Cobbinah \& Aboagye, 2017 \\
& Simon et al., 2004; Rain et al., 2011; Adaku, 2014; Cobbinah \\
Water and air pollution & et al., 2017; Cobbinah \& Aboagye, 2017 \\
Vegetation destruction & Peprah, 2014; Cobbinah et al., 2017 \\
Erosion and siltation & Peprah, 2014 \\
Flooding & Rain et al., 2011; Amoateng et al., 2013; Cobbinah et al., 2017 \\
& Peprah, 2014; Adaku, 2014; Kuusaana \& Eledi, 2015; \\
Consumption of green/open spaces & Cobbinah et al., 2017
\end{tabular}

Cobbinah \& Aboagye (2017) argued that land conversion for residential development, especially at the periphery of many cities, is unsustainable. Also, indiscriminate disposal of waste results in water pollution when it rains, as the rain washes the rubbish into water bodies. As shown in Table 1, air pollution is among the significant effects, and a critical review of the literature indicates that this is due to increased vehicular traffic as people commute from the outskirts to city centres. As people move to the suburbs to build, they cut the trees and shrubs, sometimes destroying forests, and this degrades the vegetation of the sprawled areas. The literature (Table 2) also reported that people build in waterways or wetlands, and when it rains, those properties are flooded. Some scholars were of the view that the clearing of vegetation and the construction of impervious surfaces in the outskirts increase runoff, causing flooding. Some literature also indicated that open spaces and even cemeteries were being converted dwelling places as a result of urban sprawl.

Another subtheme is the social/political and cultural effects of urban sprawl as summarised in Table 2 . 
Ghana Journal of Geography Vol. 12(1), 2020 pages 1-28

Table 2: Factors of socio-political and cultural effects of urban sprawl

\begin{tabular}{|c|c|}
\hline Factors & References \\
\hline $\begin{array}{l}\text { Increased development of } \\
\text { slum communities }\end{array}$ & Cobbinah \& Aboagye, 2017 \\
\hline $\begin{array}{l}\text { Gender, inequalities and } \\
\text { social exclusion }\end{array}$ & $\begin{array}{l}\text { Cobbinah et al., 2015, Peprah, 2014, Cobbinah et al., 2017, } \\
\text { Nyantakyi-Frimpong et al., } 2016\end{array}$ \\
\hline Loss of cultural values & Cobbinah \& Aboagye, 2017, Codjoe et al., 2016 \\
\hline Conflicts and land insecurity & $\begin{array}{l}\text { Kuusaana \& Eledi, 2015; Nyantakyi-Frimpong et al., 2016; } \\
\text { Cobbinah et al., } 2017\end{array}$ \\
\hline Increase in social vices & Peprah, 2014 \\
\hline $\begin{array}{l}\text { Extinction of indigenous } \\
\text { population }\end{array}$ & Cobbinah \& Aboagye, 2017 \\
\hline $\begin{array}{l}\text { Increased access to social } \\
\text { services }\end{array}$ & Peprah, 2014; Fuseini \& Kemp, 2016 \\
\hline
\end{tabular}

From the literature (see Table 2), urban sprawl led to the development of squatter/slum settlements in certain areas in the peri-urban areas due to the inability of the poor to acquire land or to rent, which causes them to squat at any available space. There are also increased conflicts between prospective property owners and among family members resulting from land transactions and land insecurity, leading to the engagement of land guards. The land tenure system in Ghana, and Accra in particular, is such that individuals and families own the land. There are reported cases of families breaking up into factions and fighting over the right to sell a piece of land. This has led to multiple sales in some cases, resulting in conflicts among buyers and court cases in some instances. The expansion of cities to the periphery comes with an increase in social vices such as armed robbery, stealing and rape, which were prominent in the literature (Table 2) because of wealthier people settling in the peri-urban areas. Additionally, in some cases, urban sprawl resulted in the indigenous people being outnumbered by settlers or disappearing due to cross marriages and crossfertilisation of cultural values. When this happens, most cultural norms are no longer observed, and indigenous languages may die.

In the case of health effects, the factors were poor sanitation (Simon et al., 2004; Amoateng et al., 2013; Peprah, 2014; Cobbinah et al., 2017; Cobbinah \& Aboagye, 2017) and wastewater use (Kuusaana \& Eledi, 2015; Nyantakyi-Frimpong et al., 2016,). It was evident in the articles that 
due to unsanitary conditions, there are increased incidences of malaria, diarrhoea and cholera cases, in the raining season. Other effects are related to transportation/energy including traffic congestion (Amoateng et al., 2013) and physical development outstripping utilities (water and electricity) (Amoateng et al., 2013, Cobbinah \& Aboagye, 2017). Because most of the people settling in the peri-urban areas are in the middle- to the high-income bracket; they own vehicles, thus contributing to congestion on the major roads leading to their suburban areas. Studies elsewhere (as shown in the introduction) have established the link between urban sprawl and air pollution due to increased vehicular use, but the situation is not yet clear in Ghana.

Some scientists also discussed the effects of urban sprawl on agriculture and food security. They listed factors such as loss of productive agricultural land (Amoateng et al., 2013, Kuusaana \& Eledi, 2015, Simon et al., 2004), decrease in food production (Kuusaana \& Eledi, 2015), loss of agricultural labour (Kuusaana \& Eledi, 2015), increased food prices (Kuusaana \& Eledi, 2015) and food insecurity (Peprah, 2014, Codjoe et al., 2016) as important effects. Besides agriculture, other socio-economic effects identified were economic factors such as increased government revenue (Amoateng et al., 2013), access to housing units by low- and middle-income earners (Amoateng et al., 2013), deepening poverty (Cobbinah et al., 2017, Kuusaana \& Eledi, 2015) and profit from sales of land (Peprah, 2014). Poverty was pervasive among the indigenes as they lose their economic base, i.e. their land, to residential development.

\section{Urban Sprawl in South Africa}

\section{Causes of urban sprawl in South Africa}

As shown in Figure 2, urban sprawl in South Africa has been linked to apartheid rule (Adebayo, 2012; Britz \& Meyer, 2006; Musakwa \& Van Niekerk, 2013; Musakwa \& Van Niekerk, 2014) classified here as policy cause. The apartheid government had a planning scheme that resulted in spatial and socio-economic fragmentation of the cities along racial lines (Adebayo, 2012; Musakwa \& Van Niekerk, 2013; Musakwa \& Van Niekerk, 2014). At the start of the end to apartheid in 1991, various policies implemented during the apartheid era had segmented South African cities into urban (black) African townships with limited socio-economic opportunities for majority-black African inhabitants, on the one hand, and a core and sub-urban areas dominated by 
white and Indian populations with much better employment opportunities and adequate residential and transport systems, on the other hand (Britz \& Meyer, 2006).

Population growth (Figure 2) as a result of migration also features prominently as a major cause of urban sprawl in South Africa (Britz \& Meyer, 2006; Todes, 2012). Rural-urban migration, as is the case in most SSA countries, is a major driver of urban sprawl. With decreasing agriculture output in rural areas, making it unattractive to the youth, a considerable proportion are moving to cities in search of jobs. This is resulting in an increased demand for affordable housing in the cities. Since most of these migrants including those from other SSA countries to South African cities are unable to afford housing in prime and well planned residential areas due to their high cost/rent, they are settling at the periphery of the cities where housing costs are lower (Britz \& Meyer, 2006). Improved transport systems from the CBDs to the periphery (Britz \& Meyer, 2006; De Swardt et al., 2005; Zuma, 2013) have also resulted in the sprawl of South African cities. For example, due to improved road network, many city dwellers in Cape Town, Johannesburg and Pretoria have moved to the periphery and travel to the city centre to work and shop, resulting in the sprawling of these cities. Land tenure system, population growth (Zuma, 2013), affluence (De Swardt et al., 2005) and climate change as drivers of urban sprawl have not received significant attention in the South African literature.

\section{Effects of urban sprawl in South Africa}

Socio-economic, as well as environmental effects of urban sprawl in South Africa, have received considerable focus in the articles reviewed. Studies by Todes (2012) discussed the environmental impacts of the sprawl of South Africa cities. Focusing on the changing lifestyle of people because of urban sprawl, Ewing et al. (2008) looked at the relationship between physical activity such as walking and the health of city dwellers. Also, emphasising the health impacts of sprawl, Pick \& Cooper (1997) and Pick \& Obermeyer (1996) discussed the relationship between urbanisation, household composition and the reproductive health of women, including antenatal care attendance, total number of pregnancies, the use of contraceptives and reported gynaecological illnesses. 
Some researchers have also paid attention to the effects of sprawl-induced land-use change on agriculture and food security (Rogerson, 1993). Other effects of urban sprawl that have received attention in the literature are housing (Todes, 2012) and how household energy, transportation and education have been impacted in various ways by urban sprawl. These effects have, however, not been examined extensively in the literature in South Africa. Particularly, the implication of sprawl on rural energy and transport requires research attention.

\section{Urban Sprawl in Nigeria}

\section{Causes of urban sprawl in Nigeria}

The major factors of urban sprawl identified in Nigeria include land tenure, population growth due to migration, climate change, affluence, weak regulation and transport and utilities (Sirakaya et al., 2018). The land tenure regime makes it easy for individuals to acquire land for development in urban areas, and this, coupled with increasing population due to rural-urban migration, is driving the uncontrolled expansion of the cities (Wapwera, 2014). Unenforced (poor) regulation is also contributing to urban sprawl (Moglia, 2014). With increasing numbers of people settling in cities, coupled with the limited number of urban planners in Nigerian metropolises and under-resourcing of city authorities, there is limited capacity to initiate and execute development plans in cities. In contexts where development plans exist, authorities lack the resources to monitor and enforce the development of built areas in the cities. The result is the uncontrolled and largely haphazard expansion of Nigerian cities.

\section{The effects of urban sprawl in Nigeria}

The impact of urban sprawl in Nigeria includes environmental degradation in the form of deforestation, water pollution and air pollution (Owoeye \& Ogundiran, 2014) due to unregulated land use. Linked to environmental degradation, the rapid and unplanned growth of cities leads to waste management challenges in Nigeria, exposing people to various health hazards (Oyeyemi et al., 2012; Owoeye \& Ogundiran, 2014). The health effects of urban sprawl in the literature 
highlighted how the changing activity type and movement pattern of people affect their health (Tofowomo, 2008). Oyeyemi et al. (2012), for instance, examined the environmental factors associated with overweight adults in Nigeria. Defining overweight as body mass index (BMI) greater than 25, they identified remote access to commercial facilities, poor neighbourhood aesthetics, crime and traffic congestion which makes walking unsafe, as being among the factors that cause people to be overweight. All the literature reviewed identified encroachment on agriculture land as a major effect of urban sprawl in Nigeria. The unregulated expansion of cities is leading to the conversion of agricultural land to residential, industrial and commercial land uses. As urban sprawl engulfs rural agrarian economies, there will be negative consequences for sociocultural systems in rural communities as well as food security and rural livelihoods.

\section{Urban Sprawl in Kenya}

\section{Causes of Urban Sprawl in Kenya}

Population growth due to rural-urban migration was found to be the most significant cause of urban sprawl in Kenya (Omwenga, 2010; Adebayo, 2012; Mubea \& Menz, 2012; Simiyu, 2012; Steyn, 2012). According to Mubea \& Menz (2012), the city of Kisumu has about $60 \%$ of its population living in dense, congested informal settlements. Ngayu (2011) also postulates that the urban population of Kenya is estimated to expand to 38 million by 2030 and to account for about $60 \%$ of the national population. Evidence of rural-urban migration is seen in the density of the population in cities in Kenya. There have been increasing densities in both low rise and high rise informal settlements as is the case in Kibera where densities as high as over 2000 people per hectare are typical. There is also a high-rise settlement called Zimmerman located on the periphery of Nairobi. This neighbourhood is characterised by congestion and poor infrastructure resulting in a poor-quality environment.

The second major cause of urban sprawl is the land tenure systems which make land acquisition in urban areas easier, coupled with policy deficiencies (Nicodemus \& Ness, 2010; Steyn, 2012; Binswanger-Mkhize et al., 2016). The Kenyan government has over the last decades pursued policies geared towards the promotion of secondary towns. This has made the acquisition and ownership of land relatively easier in the urban areas, thereby increasing the influx into urban 
communities. However, these policies have not been structured to accommodate the management of rural-urban migration and its attendant problems. Several cities in SSA such as Kampala, Lagos and Accra have grown beyond their zoned/planned areas, resulting in the coexistence of residential, industrial, commercial and agricultural land use simultaneously. This, in addition to the sprawl of cities, has significant implications for livelihoods and the environment (Omwenga, 2010). Climate change is seen as another cause of urban sprawl in Kenya (Omwenga, 2010) as it largely affects agriculture, resulting in poor income for rural households and forcing them to move to urban areas for better opportunities.

\section{Effects of Urban Sprawl in Kenya}

The effects of urban sprawl in Kenya were categorised according to their influence on the communities and the economy on the whole. The main categories considered the effects of urban sprawl on the environment, health, social and political situations, economic impacts, agriculture, energy and housing (Figure 3). For instance, the impact of urban sprawl on housing in Kenya includes the encroachment of residential and commercial land use on farmlands. The uncontrolled expansion of Kenyan cities is also leading to the destruction of ecological wetlands by the conversion of such lands into residential areas. In Nairobi, urbanisation has caused the city to encroach on green spaces such as nearby parks and forests. The consequences of urban sprawl can be economic, physical, social, emotional and aesthetic. Economic effects include increased health burden (Steyn, 2012, Mubea \& Menz, 2012) cost of infrastructure, loss of farm and forest lands (Nicodemus \& Ness, 2010; Simiyu, 2012), urban decay, greater fiscal disparities among localities, depletion of environmental resources (Omwenga, 2010; Adebayo, 2012; Simiyu, 2012; Binswanger-Mkhize et al., 2016), higher tax burden, and higher land prices. Physically, urban sprawl has resulted in congested roads and overcrowded markets. The emotional consequences of urban sprawl in Kenya are a loss of community spirit and a sense of ownership of land (Simiyu, 2012). Although an estimated $80 \%$ of Kenya's economy relies on agriculture (Mubea et al., 2014), only about $20 \%$ of the country's landmass can support rain-fed farming. The uncontrolled expansion of Kenyan cities is putting massive pressure on land for agricultural purposes (Binswanger-Mkhize et al., 2016). Other issues of focus in the literature include the impact of urban sprawl on transport and utilities (Nicodemus \& Ness, 2010; Simiyu, 2012). 


\section{Discussion}

Our search indicates that urban sprawl in SSA has received considerable attention. Given that the databases consulted represent a fraction of all databases that African scholars and their collaborators as well as other researchers outside the sub-region publish in, and yet returned this number of articles, we can confidently say that there is a high level of knowledge on urban sprawl in SSA. While there is considerable research on SSA, it still lags behind many other regions (Ji et al., 2006).

It is evident from Figure 2 that the prominence of the factors constituting causes varies across countries. For example, in Ghana, more studies are focused on policy failures as a cause of urban sprawl while in Kenya population growth received more prominence. Climate change as a cause of urban sprawl is less reported across the countries. This could be because climate change is considered a remote cause, contributing to rural-urban migration. Except for Ghana, affluence (an economic measure ranging from poor to rich) receives less attention in the literature. It is also worth noting that while the factors varied among the countries, some were the same. Differences could be associated with cultural variations in various countries. For example, the customary land tenure system in Ghana may be different from what pertains in the other countries, and this could cause a variation in the factors that make land tenure system a cause of urban sprawl.

The effects of urban sprawl also exhibit some patterns. From Figure 3, the effects were more prominently considered in East and West African countries. On average, Kenya has the highest number of researches on the effects of urban sprawl. Whereas environmental, health, income and housing effects were of concern to researchers in Kenya, only social impacts and, to some extent, housing were important in South Africa. Nigerian researchers recognised all subthemes as key effects, while in Ghana, the critical effects were mainly on the environment, agriculture, and transport.

Urban growth is happening in the study countries, and as indicated by UN-DESA (2014), the cities will continue to grow with the urban population estimated to hit $56 \%$ by 2050 . Among the four sub-regions in SSA, West Africa is the fastest-growing sub-region with the population expected 
to exceed 1.3 billion while central Africa is the slowest with an estimated population of less than 200 million by 2050 (UNECA, 2017). Thus, the growth of most cities in the sub-regions is so rapid that urban sprawl is inevitable. It is demonstrated in this paper that urban sprawl is accompanied with a lot of effects, both environmental and human. Although there are studies on the effects of urban sprawl, there is still a paucity of critical studies on how each of the themes or factors is/are influencing urban sprawl in SSA. For example, in many developed countries, specific studies have been undertaken on fuel consumption, the efficiency of energy use, climate change, greenhouse gas emissions, and loss of energy through transmission relating to urban sprawl (Madlener \& Sunak, 2011; Ahmadi, 2014; Rodríguez-Álvarez, 2016). Most of these studies have provided useful information on urban energy planning and on managing urbanisation in general (see Madlener \& Sunak, 2011). Such studies are critical in SSA as it is a sub-region where about $48 \%$ of the global population has no access to electricity (Castellano et al., 2015). Yet, projections of climate change impacts particularly on electricity in SSA is high (Edenhofer et al., 2014) and the city dwellers are increasingly using energy-consuming electrical appliances and putting up housing units which require energy mostly for cooling (Madlener \& Sunak, 2011). There is the need for research to determine the type and trend of demand to enable governments to plan effectively to meet such demand. New forms of energy such as liquefied petroleum gas (LPG) have also emerged in the sprawled areas, but studies linking these new forms of energy to urban sprawl as well as comparing them to the biofuels (charcoal and firewood) use are very critical in the face of increasing effects of climate change.

The environmental impact of urban sprawl in SSA is still generic, while some continents and countries have delved into specifics. For example, in some developed countries, water demand/supply, air pollution and their relationship with urban sprawl have been explored. Brook et al. (2008), for instance, examined the link between diabetes mellitus and traffic-related air pollution and found a positive relationship. They, however, called for further research to determine whether or not the link is a cause-and-effect one. Tu et al. (2007) also examined the impacts of urban sprawl on the quality of water in Massachusetts and found that the effects stem from the impact of population and land-use change. These and many other environmental impacts and health-related studies are very useful in SSA, which is experiencing most of these health challenges 
(BeLue et al., 2009). Health issues are likely to become critical shortly as African cities continue to grow and sprawl at an alarming rate. These issues will be fundamental considering the way urban sprawl is reported to be taking place in the countries without regard to any land use plan, resulting in land-use conflicts (mixed uses) with both environmental and health consequences. The transportation sector is also less investigated because the few studies available examined the relationship between improvement in road networks and urban sprawl. Studies in the United States and Canada for example (Frumkin, 2002) have instead examined the impacts that increase in vehicular use as a result urban sprawl has on air pollution, greenhouse gas emissions, physical activity and health challenges. Studies like these, including the impact of sprawl on non-motorised modes of transport, are critical in SSA. The research we reviewed indicates that in many cases physical development in peri-urban areas does not follow proper planning schemes and thus results in a type of physical development that gives little or no consideration to open spaces and makes no provision for biking or walking, which has implications for physical activity and is linked to health challenges in other regions (e.g. Frumkin, 2002).

Issues of agriculture, income and social outcomes of urban sprawl are also generic. These can be described as socio-economic or livelihood facing. Most of the reviewed articles focus on the negative impacts of urban sprawl on livelihoods, especially agriculture and food insecurity, loss of income and cultural values, among others. However, urban sprawl has some potential positive outcomes such as new forms of employment, utilities and social amenities. Some of these livelihood activities may also be out of reach for many people living in the newly developed areas due to poverty or lack of skills. This means that a cost/benefit analysis (which is scarce in the literature) accounting for spatial and temporal differences is required, to determine the overall impact of urban sprawl on livelihoods.

The review indicates some variations in research focus or reports among the countries, but this is not peculiar to the SSA countries; similar variations have been reported in studies from other regions (Pendall, 1999; Bart, 2010; Habibia \& Asadi, 2011; Osman et al., 2016). Also absent in the literature on urban sprawl are comparative studies even for cities within countries. However, such studies are needed as they will contribute greatly to enhancing the understanding of factors responsible for the intra-country and inter-country variations of urban sprawl identified above. A 
comparative study will further enable knowledge and best practice sharing, thereby helping find African ways of dealing with African problems, as external solutions do not usually work on the continent (Casimir et al., 2014). We also observed from the literature that the methods used in the studies vary and few studies incorporate in their data analysis modern techniques such as Remote Sensing and GIS which can, in combination with other methods, provide a detailed understanding of urban sprawl.

As urbanisation (i.e. the growth of urban areas) in SSA intensifies, the linkages between rural and urban areas increase while their differences decrease (UN-Habitat, 2015). One of the phenomena that bring about this change in the linkage is the flow of people from rural to urban areas. Urban growth, especially in developing countries, is primarily due to migration from rural areas to urban centres (Misilu et al., 2010). The migrants, upon arrival, increase the demand for shelter and other social infrastructure. This demand, as gathered from the reviewed articles, is most often met by converting lands in the periphery of the cities for housing. The land conversion reported in the articles is uncontrolled and uncoordinated; it results in sprawling of cities beyond their frontiers and into neighbouring rural areas. In fact, from the studies, some of the rural areas have become part of the cities. This means that some urban areas now have the characteristics of both urban and rural areas. Thus, the traditional conception of urban and rural areas as distinct geographic entities are changing as the geographic boundaries between them is decreasing/blurring due to urban sprawl. The movement of people from rural areas to urban areas results in an inflow of knowledge, economic resources and information between urban and rural areas (Rodriguez, 2014). Other interactions discussed in the literature are changing lifestyles, loss of livelihoods and cultural values, and increasing social vices, among others, attributed to urban sprawl. Urban sprawl is thus contributing to the changing dynamics of urban and rural areas and increasing the linkage between these geographic entities. 


\section{Conclusion}

The review has demonstrated that there is considerable research on urban sprawl in SSA countries. The effects and implications of urban sprawl on the rural poor were studied from the selected SSA countries. Urban sprawl was investigated with different lenses, although the literature is not widely diversified. Urban sprawl has been found to have an impact on land use, water use, the environment and health. However, there is still much more to be learnt. We have identified several research gaps, most of which have a bearing on the SDGs and therefore investigating them will contribute to achieving the SDGs. First of all, we found that there is some level of knowledge about urban sprawl in Africa. But compared with the developed world, we find most of the studies on urban sprawl in SSA still more generic focusing, at the broad level, on causes and effects while little is known about the relationship between specific factors of global or national concern. For example, while the developed world is concerned with issues like the link between urban sprawl and diabetes or hypertension, Africa is still studying the relationship with health in general. Other knowledge gaps we identified include lack of comparative studies of cities within and across African countries, the paucity of knowledge on the spatial variations of urban sprawl, a cost/benefit analysis to determine the actual impacts of urban sprawl, among others. Moreover, in the literature investigated, very few studies have used modern methods to quantitatively analyse urban sprawl, and this poses a challenge for policymaking and land use planning. We acknowledge here that the phenomenon of urban sprawl is complex, and our list of research gaps is by no means exhaustive; therefore, a holistic, integrated approach to studying urban sprawl may be required. There is, therefore, the need for further research to gain a deeper understanding of the threats and opportunities associated with urban sprawl and design policies and programs for sustainable urban and rural development. 


\section{References}

Adaku, E. (2014). Urban sprawl: a view from developing and developed countries. African Journal of Geography and Regional Planning, 1(6), 193-207.

Adebayo, A. A. (2012). A Tale of Two African Cities: Hyper Growth, Sprawl and Compact City Development. Paper presented at the 48th ISOCARP Congress: Towards the Development of a Sustainable Future City.

Ahmadi, L. (2014). The Impact Of Sprawl On Transportation Energy Consumption And Transportation Carbon Footprint In Large US Cities. (Unpublished doctoral dissertation), University of Texas at Arlington, Texas, USA.

Amoateng, P., B Cobbinah, P., \& Owusu-Adade, K. (2013). Managing physical development in peri-urban areas of Kumasi, Ghana: A case of Abuakwa. Journal of Urban and Environmental Engineering, 7(1).

Bart, I. L. (2010). Urban sprawl and climate change: A statistical exploration of cause and effect, with policy options for the EU. Land Use Policy, 27(2), 283-292.

BeLue, R., Okoror, T. A., Iwelunmor, J., Taylor, K. D., Degboe, A. N., Agyemang, C., \& Ogedegbe, G. (2009). An overview of cardiovascular risk factor burden in sub-Saharan African countries: a socio-cultural perspective. Globalisation and Health, 5(1), 10.

Binswanger-Mkhize, H. P., Johnson, T., Samboko, P. C., \& You, L. (2016). The impact of urban growth on agricultural and rural non-farm growth in Kenya. International Fund for Agricultural Development, Rome

Bristow, D. N., \& Kennedy, C. A. (2013). Urban metabolism and the energy stored in cities: Implications for resilience. Journal of Industrial Ecology, 17(5), 656-667.

Britz, A., \& Meyer, E. (2006). Whose line is it anyway?: The origin and evolution of the Gauteng Urban Edge. Town Planning Review, 77(2), 205-219.

Brook, R. D., Jerrett, M., Brook, J. R., Bard, R. L., \& Finkelstein, M. M. (2008). The relationship between diabetes mellitus and traffic-related air pollution. Journal of Occupational and Environmental Medicine, 50(1), 32-38.

Casimir, A., Omeh, E., \& Ike, C. C. (2014). Poverty and Governance-A Critical Appraisal of a Philosophy and Practice of Development in Africa. Open Journal of Political Science, 4(03), 164. 
Ghana Journal of Geography Vol. 12(1), 2020 pages 1-28

Castellano, A., Kendall, A., Nikomarov, M., \& Swemmer, T. (2015). Brighter Africa: The growth potential of the sub-Saharan electricity sector. McKinsey and Company. http://www.mckinsey.com/insights/energy_resources_materials/powering_africa

Cobbinah, P. B., \& Aboagye, H. N. (2017). A Ghanaian twist to urban sprawl. Land Use Policy, 61, 231-241.

Cobbinah, P. B., Gaisie, E., \& Owusu-Amponsah, L. (2015). Peri-urban morphology and indigenous livelihoods in Ghana. Habitat International, 50, 120-129.

Cobbinah, P. B., Poku-Boansi, M., \& Peprah, C. (2017). Urban environmental problems in Ghana. Environmental Development. doi:10.1016/j.envdev.2017.05.001

Codjoe, S. N., Okutu, D., \& Abu, M. (2016). Urban Household Characteristics and Dietary Diversity: An Analysis of Food Security in Accra, Ghana. Food Nutrition Bulletin, 37(2), 202-218.

De Swardt, C., Puoane, T., Chopra, M., \& Du Toit, A. (2005). Urban poverty in Cape Town. Environment and Urbanisation, 17(2), 101-111.

Dialogue. http://policy-practice.oxfam.org.uk/publications/the-newurban-towards-

Edenhofer O, Pichs-Madruga R, Sokona Y, Agrawala S, Bashmakov IA, Blanco G, Broome J, Bruckner T. (2014). Summary for policymakers. In: Climate Change 2014: Mitigation of Climate Change. IPCC Working Group III Contribution to AR5. Cambridge University Press.

Ewing, R., Schmid, T., Killingsworth, R., Zlot, A., \& Raudenbush, S. (2008). Relationship Between Urban Sprawl and Physical Activity, Obesity, and Morbidity. Urban Ecology, 567-582.

Frumkin, H. (2002). Urban sprawl and public health. Public Health Reports, 117(3), 201.

Fuseini, I., \& Kemp, J. (2015). A review of spatial planning in Ghana's socio-economic development trajectory: A sustainable development perspective. Land Use Policy, 47, 309320.

Fuseini, I., \& Kemp, J. (2016). Characterising urban growth in Tamale, Ghana: An analysis of urban governance response in infrastructure and service provision. Habitat International, $56,109-123$.

Fuseini, I., Yaro, J. A., \& Yiran, G. A. (2017). City profile: Tamale, Ghana. Cities, 60, 64-74.

Habibi, S., \& Asadi, N. (2011). Causes, results and methods of controlling urban sprawl. Procedia Engineering, 21, 133-141. 
Hove, M., Ngwerume, E., \& Muchemwa, C. (2013). The urban crisis in Sub-Saharan Africa: A threat to human security and sustainable development. Stability: International Journal of Security and Development, 2(1).

Huang, X., Zhao, D., Brown, C. G., Wu, Y., \& Waldron, S. A. (2010). Environmental issues and policy priorities in China: a content analysis of government documents. China: An International Journal, 8(02), 220-246.

Ji, W., Ma, J., Twibell, R. W., \& Underhill, K. (2006). Characterising urban sprawl using multistage remote sensing images and landscape metrics. Computers, Environment and Urban Systems, 30(6), 861-879.

Johnson, M. P. (2001). Environmental impacts of urban sprawl: a survey of the literature and proposed research agenda. Environment and Planning A, 33(4), 717-735.

Kleemann, J., Baysal, G., Bulley, H. N., \& Fürst, C. (2017). Assessing driving forces of land use and land cover change by a mixed-method approach in north-eastern Ghana, West Africa. Journal of Environmental Management, 196, 411-442.

Kuusaana, E. D., \& Eledi, J. A. (2015). As the city grows, where do the farmers go? Understanding Peri-urbanization and food systems in Ghana - Evidence from the Tamale Metropolis. Urban Forum, 26(4), 443-465.

Liu, Y., Yue, W., \& Fan, P. (2011). Spatial determinants of urban land conversion in large Chinese cities: a case of Hangzhou. Environment and Planning B: Planning and Design, 38(4), 706-725.

Madlener, R., \& Sunak, Y. (2011). Impacts of urbanisation on urban structures and energy demand: What can we learn for urban energy planning and urbanisation management? Sustainable Cities and Society, 1(1), 45-53.

Misilu, M., Nsokimieno, E., Chen, S., Zhang Li, Q. (2010). Sustainable urbanisation's challenge in Democratic Republic of Congo. Journal of Sustainable Development, 3(2), 242.

Moglia, M. (2014). Urban agriculture and related water supply: Explorations and discussion. Habitat International, 42, 273-280.

Mubea, K., \& Menz, G. (2012). Monitoring land-use change in Nakuru (Kenya) using multi-sensor satellite data. Advanced Remote Sensing 1, 74-84

Mubea, K., Goetzke, R., \& Menz, G. (2014). Applying cellular automata for simulating and assessing urban growth scenario based in Nairobi, Kenya. International Journal of Advanced Computer Science and Applications, 5(2),1-13. 
Musakwa, W., \& Van Niekerk, A. (2013). Implications of land use change for the sustainability of urban areas: A case study of Stellenbosch, South Africa. Cities, 32, 143-156.

Musakwa, W., \& van Niekerk, A. (2014). Monitoring Urban Sprawl and Sustainable Urban Development Using the Moran Index. International Journal of Applied Geospatial Research, 5(3), 1-20.

Ngayu, M. N. (2011). Sustainable urban communities: Challenges and opportunities in Kenya's urban sector. International Journal of Humanities and Social Science, 1(4), 71-76.

Nicodemus, M., \& Ness, B. (2010). Peri-urban development, livelihood change and household income: A case study of peri-urban Nyahururu, Kenya. Journal of Agricultural Extension and Rural Development, 2(5), 73-83.

Nyantakyi-Frimpong, H., Arku, G., \& Inkoom, D. K. B. (2016). Urban agriculture and political ecology of health in municipal Ashaiman, Ghana. Geoforum, 72, 38-48.

Omwenga, M. (2010). Nairobi-Emerging metropolitan region: Development planning and management opportunities and challenges. ISOCARP CONGRESS, 26.

Oppong, R., \& Yeboah, E. (2013). Empirical Examinations of Conflicts and Contradictions in Architecture, Land and Suburban Sprawl: The Case of Tamale, Ghana. Journal of Science and Technology (Ghana), 33(1), 92-104.

Osman, T., Arima, T., \& Divigalpitiya, P. (2016). Measuring Urban Sprawl Patterns in Greater Cairo Metropolitan Region. Journal of the Indian Society of Remote Sensing, 44(2), 287295.

Owoeye, J., \& Ogundiran, A. (2014). A study on housing and environmental quality of Moniya Community in Ibadan, Nigeria. Journal of Environment and Earth Science, 4(13), 51-60.

Owusu, G. (2013). Coping with urban sprawl: A critical discussion of the urban containment strategy in a developing country city, Accra. Planum, The Journal of Urbanism, 1, 1-17.

Oyeyemi, A. L., Adegoke, B. O., Oyeyemi, A. Y., Deforche, B., De Bourdeaudhuij, I., \& Sallis, J. F. (2012). Environmental factors associated with overweight among adults in Nigeria. International Journal of Behavioral Nutrition and Physical Activity, 9(1), 32.

Pendall, R. (1999). Do land-use controls cause sprawl? Environment and Planning B: Planning and Design, 26(4), 555-571.

Peprah, K. (2014). Urban sprawl of Wa, Ghana: Socio-economic implications for small-holder farmers. International Journal of Innovative Research and Development, 3(1), 277-288. 
Pick, W. M., \& Obermeyer, C. M. (1996). Urbanisation, household composition and the reproductive health of women in a South African city. Social Science \& Medicine, 43(10), 1431-1441.

Pick, W., \& Cooper, D. (1997). Urbanisation and women's health in South Africa. African Journal of Reproductive Health, 45-55. progressive-secondary-cities-336561

Rain, D., Engstrom, R., Ludlow, C., \& Antos, S. (2011). Accra Ghana: A city vulnerable to flooding and drought-induced migration. Case study prepared for cities and climate Change: Global Report on Human Settlements, 2011, 1-21.

Rodriguez, C. J. (2014). The New Urban: Towards Progressive Secondary Cities; Asian Development. http://policy-practice.oxfam.org.uk/publications/the-newurban-towardsprogressive-secondary-cities-336561.

Rodríguez-Álvarez, J. (2016). Urban Energy Index for Buildings (UEIB): A new method to evaluate the effect of urban form on buildings' energy demand. Landscape and Urban Planning, 148, 170-187.

Rogerson, C. M. (1993). Urban agriculture in South Africa: Scope, issues and potential. GeoJournal, 30(1), 21-28.

Saghir, J., \& Santoro, J. (2018). Urbanisation in Sub-Saharan Africa: Meeting Challenges by Bridging Stakeholders Center for Strategic and International Studies (CSIS). https://www.csis.org/analysis/urbanization-sub-saharan-africa

Simiyu, R. R. (2012). “I Don't Tell My Husband about Vegetable Sales”: Gender Dynamics in Urban Agriculture in Eldoret, Kenya. Leiden: African Studies Centre.

Simon, D., McGregor, D., \& Nsiah-Gyabaah, K. (2004). The changing urban-rural interface of African cities: definitional issues and an application to Kumasi, Ghana. Environment and Urbanisation, 16(2), 235-248.

Sirakaya, A., Cliquet, A., \& Harris, J. (2018). Ecosystem services in cities: Towards the international legal protection of ecosystem services in urban environments. Ecosystem Services, 29, 205-212.

Steyn, G. (2012). Modernity and Informality-Conflicting Forces Shaping Urban Form in Kisumu, Kenya. International Journal for Housing Science and Its Applications, 36(3), 171.

Todes, A. (2012). Urban growth and strategic spatial planning in Johannesburg, South Africa. Cities, 29(3), 158-165. 
Ghana Journal of Geography Vol. 12(1), 2020 pages 1-28

Tofowomo, A. (2008). The planning implications of Urban Sprawl in Akure. 44th ISOCARP Congress, Nigeria.

Tu, J., Xia, Z.-G., Clarke, K. C., \& Frei, A. (2007). Impact of urban sprawl on water quality in eastern Massachusetts, USA. Environmental Management, 40(2), 183-200.

UN. (2006). World urbanisation prospects: the 2005 revision: United Nations Publications.

UN-DESA. (2011). In Population Distribution, Urbanization, Internal Migration and Development: An International Perspective. United Nations Department of Economic and Social Affairs, 161-195.

UN-DESA. (2014). United Nations Department of Economic and Social Affairs (2015): World Urbanization Prospects: The Department of Economic and Social Affairs of the United Nations, Population Division. : New York, NY, USA.

UNECA. (2017). An Overview of Urbanization and Structural Transformation in Africa. Economic Report on Africa 2017: United Nations Economic Commission for Africa: Addis Ababa, Ethiopia.

UN-Habitat. (2009). Planning sustainable cities: Global report on human settlements 2009: Earthscan

UN-Habitat. (2015). Habitat III issue Papers: 10-Urban-Rural Linkages: New York.

Wapwera, S. D. (2014). Spatial planning framework for urban development and management in Jos Metropolis Nigeria. The University of Salford.

Wesley, J. J. (2010). Qualitative document analysis in political science. T2PP Workshop. Amsterdam: Vrije Universiteit.

White, M. J., Mberu, B. U., \& Collinson, M. A. (2008). African urbanisation: Recent trends and implications. The New Global Frontier Urbanization, Poverty and Environment in the 21st Century.

Yiran, G. A., \& Stringer, L. C. (2017). Adaptation to Climatic Hazards in the Savannah Ecosystem: Improving Adaptation Policy and Action. Environmental Management, 60(4), 665-678.

Zuma, N. (2013). Rural-urban migration in South Africa. Paper presented at the Economic Policy Forum for growth, transformation, reform: Emerging economies in the next decade, Haikou, China. 